\title{
Controller Reduction with Combination of Generalized Gramians
}

\author{
Kentaro Asato Student Member (University of the Ryukyus, k058651@eve.u-ryukyu.ac.jp) \\ Tsutomu Nagado Member (University of the Ryukyus, nagado@tec.u-ryukyu.ac.jp) \\ Shiro Tamaki Member (University of the Ryukyus, shiro@ie.u-ryukyu.ac.jp)
}

Keywords: controller reduction, generalized Gramians, coprime factorization, structurally balanced truncation

In this paper, a new controller reduction method using generalized Gramians (generalized controllability and observability Gramians) is proposed. In order to obtain the generalized Gramians which have block diagonal structure, a considering control system is described by using right and left coprime factorizations of the plant and the controller. For the system and its subsystems (sensitivity function etc.), $\mathcal{H}_{\infty}$ error norms of the subsystems (the system) with a reducedorder controller yield an upper bound of $\mathcal{H}_{\infty}$ performance of the system (each subsystem) with the reduced-order controller. From the viewpoint of the relation, the reducedorder controllers in the proposed method are obtained with combination of the structured generalized Gramians of the subsystems.

We consider the closed-loop system (which is internally stable) shown in Fig.1 where the generalized plant $G$ is given by

$$
\begin{aligned}
& w=\left[\begin{array}{lll}
w_{1}^{\mathrm{T}} & w_{2}^{\mathrm{T}} & w_{3}^{\mathrm{T}}
\end{array}\right], \quad z=\left[\begin{array}{ll}
z_{1}^{\mathrm{T}} & z_{2}^{\mathrm{T}}
\end{array}\right], \\
& {\left[\begin{array}{c}
z_{1} \\
z_{2} \\
\hdashline e^{-}
\end{array}\right]=\left[\begin{array}{ccc:c}
G_{z_{1} w_{1}} & G_{z_{1} w_{2}} & G_{z_{1} w_{3}} & G_{z_{1}} \\
G_{z_{2} w_{1}} & G_{z_{2}} w_{2} & G_{z_{2}} w_{3} & G_{z_{2}} \\
\hdashline G_{w_{1}} & G_{w_{2}} & G_{w_{3}} & G_{p}^{\underline{2}}
\end{array}\right]\left[\begin{array}{c}
w_{1} \\
w_{2} \\
w_{3} \\
\hdashline \bar{u}
\end{array}\right]}
\end{aligned}
$$

and $K$ is a controller for $G$. It is easy to shown that the transfer function $T_{z w}$ from $w$ to $z$ is given by

$$
\begin{aligned}
T_{z w} & =\mathcal{F}_{l}(G, K) \\
& =\left[\begin{array}{lll}
T_{z_{1} w_{1}} & T_{z_{1} w_{2}} & T_{z_{1} w_{3}} \\
T_{z_{2} w_{1}} & T_{z_{2} w_{2}} & T_{z_{2} w_{3}}
\end{array}\right] \in \mathcal{R H}_{\infty}, \\
T_{z_{i} w_{j}} & =G_{z_{i} w_{j}}+G_{z_{i}} K\left(I-G_{p} K\right)^{-1} G_{w_{j}}, \\
i & =1,2, \quad j=1,2,3
\end{aligned}
$$

where $\mathcal{F}_{l}(\cdot, \cdot)$ is the linear fractional transformation.

The proposed controller reduction procedure consists of the following three steps:

\section{!ZController reduction procedure! [}

Step 1 (Description of a control system)

Find coprime factors of $G_{p}$ and $K$ such that

$$
\begin{aligned}
& G_{p}=U_{r} V_{r}^{-1}=V_{l}^{-1} U_{l} \\
& U_{r}, U_{l}, V_{r}, V_{l} \in \mathcal{R} \mathcal{H}_{\infty}, \\
& K=X_{r} Y_{r}^{-1}=Y_{l}^{-1} X_{l}, \\
& X_{r}, X_{l}, Y_{r}, Y_{l} \in \mathcal{R} \mathcal{H}_{\infty}, \\
& {\left[\begin{array}{cc}
V_{l} & -U_{l} \\
X_{l} & Y_{l}
\end{array}\right]\left[\begin{array}{cc}
Y_{r} & U_{r} \\
-X_{r} & V_{r}
\end{array}\right]=\left[\begin{array}{ll}
I & 0 \\
0 & I
\end{array}\right] .}
\end{aligned}
$$

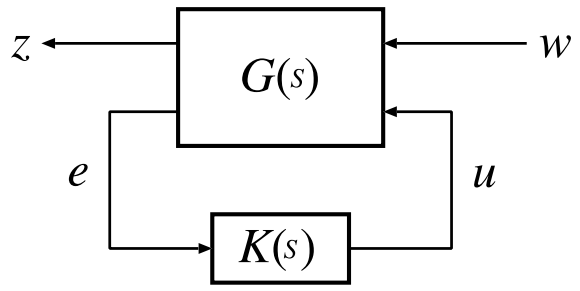

Fig. 1. Closed-loop system

Define

$$
\begin{aligned}
T_{i j}^{f} & =\mathcal{F}_{l}\left(G_{i j}^{f}, S_{i j}^{f}\right)=T_{z_{i} w_{j}} \\
& =\left[\begin{array}{l|l}
A_{i j}^{f} & B_{i j}^{f} \\
\hline C_{i j}^{f} & D_{i j}^{f}
\end{array}\right], \\
f & =r, l
\end{aligned}
$$

where $T_{i j}^{f}$ is the transfer function from $w_{j}$ to $z_{i}$ with the minimal realization such that $S_{i j}^{f}$ is equal to the coprime factor of $K\left(X_{f}\right.$ or $\left.Y_{f}\right)$.

\section{Step 2 (Calculation of generalized Gramians)}

Solve the following Lyapunov inequalities for each $T_{i j}^{f}$

$$
\begin{aligned}
& A_{i j}^{f} \mathcal{P}+\mathcal{P} A_{i j}^{f^{\mathrm{T}}}+B_{i j}^{f} B_{i j}^{f^{\mathrm{T}}} \leq 0, \mathcal{P}=\operatorname{diag}\left(\mathcal{P}_{g}, \mathcal{P}_{k}\right) \geq 0, \\
& A_{i j}^{f^{\mathrm{T}}} \mathcal{Q}+\mathcal{Q} A_{i j}^{f}+C_{i j}^{f \mathrm{~T}} C_{i j}^{f} \leq 0, \mathcal{Q}=\operatorname{diag}\left(\mathcal{Q}_{g}, \mathcal{Q}_{k}\right) \geq 0
\end{aligned}
$$

where $\mathcal{P}_{g}$ and $\mathcal{P}_{k}$ (also, $\mathcal{Q}_{g}$ and $\mathcal{Q}_{k}$ ) have the same size as $G_{i j}^{f}$ and $S_{i j}^{f}$, respectively. Now we define $\mathcal{P}\left\{T_{i j}^{f}\right\}$ and $\mathcal{Q}\left\{T_{i j}^{f}\right\}$ as a structured generalized controllability Gramian and a structured generalized observability Gramian of $T_{i j}^{f}$, respectively.

\section{Step 3 (Controller reduction)}

For convenience, a combination of the balanced generalized Gramians is written by $\left(\mathcal{P}\left\{T_{i_{1} j_{1}}^{f_{1}}\right\}, \mathcal{Q}\left\{T_{i_{2} j_{2}}^{f_{2}}\right\}\right)_{b}$ and the reduced-order controller with the combination is written by $\hat{K}\left[\left(\mathcal{P}\left\{T_{i_{1} j_{1}}^{f_{1}}\right\}, \mathcal{Q}\left\{T_{i_{2} j_{2}}^{f_{2}}\right\}\right)_{b}\right]$. Finding reduced-order controllers for all the combinations, we can obtain the reducedorder controller $\hat{K}_{\text {opt }}$ such that

$$
\begin{aligned}
& \left\|\mathcal{F}_{l}\left(G, \hat{K}_{\text {opt }}\right)\right\|_{\infty}= \\
& \min _{\left(i_{1}, j_{1}, f_{1}\right),\left(i_{2}, j_{2}, f_{2}\right)}\left\|\mathcal{F}_{l}\left(G, \hat{K}\left[\left(\mathcal{P}\left\{T_{i_{1} j_{1}}^{f_{1}}\right\}, \mathcal{Q}\left\{T_{i_{2} j_{2}}^{f_{2}}\right\}\right)_{b}\right]\right)\right\|_{\infty} .
\end{aligned}
$$

Finally, several numerical examples are used to verify the availability of the proposed method. 


\title{
一般化グラミアンの組合せによるコントローラの低次元化
}

\author{
学生員 安里 健太郎* 正 員 長堂 勤** \\ 正 員 玉城 史朗**
}

Controller Reduction with Combination of Generalized Gramians

Kentaro Asato*, Student Member, Tsutomu Nagado**, Member, Shiro Tamaki**, Member

In this paper, a new controller reduction method using generalized Gramians (generalized controllability and observability Gramians) is proposed. In order to obtain the generalized Gramians which have block diagonal structure, a considering control system is described by using right and left coprime factorizations of the plant and the controller. For the system and its subsystems (sensitivity function etc.), $\mathcal{H}_{\infty}$ error norms of the subsystems (the system) with a reduced-order controller yield an upper bound of $\mathcal{H}_{\infty}$ performance of the system (each subsystem) with the reduced-order controller. From the viewpoint of the relation, the reduced-order controllers in the proposed method are obtained with combination of the structured generalized Gramians of the subsystems. Finally, several numerical examples are used to verify the availability of the proposed method.

キーワード : コントローラ低次元化, 一般化グラミアン, 既約分解, 構造化平衡打ち切り法

Keywords: controller reduction, generalized Gramians, coprime factorization, structurally balanced truncation

\section{1. はじめに}

大規模な実システムに対して設計された高次元コントロー ラの次数を低くすることは，コストや維持・管理などの観 点から, 重要な課題となっている。コントローラの低次元 化は，一般に，モデル（フィルタやプラントなど）の低次 元化と区別される。モデル低次元化問題において，低次元 化されたモデルの近似の良さは，その入出力特性で評価さ れることが多い。これに対し，低次元化されたコントロー ラの近似の良さは，その入出力特性のみで評価することが できない。コントローラは, 制御システムの安定化や性能 改善を目的として設計・実装される。そのため, 低次元化 コントローラには, 制御システムの安定化や許容内の制御 性能が要求されてくる。

フィードバックコントローラの低次元化では，これらの 要求を達成するために, 閉ループ特性を考える必要がある。

\footnotetext{
* 琉球大学大学院理工学研究科

₹ 903-0213 沖縄県中頭郡西原町字千原 1

Graduate School of Science and Engineering, University of the Ryukyus

1 Senbaru, Nishihara-cho, Nakagami-gun, Okinawa 903-0213

** 琉球大学工学部

干 903-0213 沖縄県中頭郡西原町字千原 1

Faculty of Engineering, University of the Ryukyus

1 Senbaru, Nishihara-cho, Nakagami-gun, Okinawa 903-0213
}

Enns ${ }^{(1)}$ は, 閉ループシステムの安定性を考慮するために, 周波数に依存した重み関数を導入し, 重みつき低次元化問 題に帰着したコントローラ低次元化法を考案した。その後, Lin ら (2) やWang ら (3) が Enns の重みつき低次元化法を 発展させ, また, 多くの研究により, さまざまな観点から重 み関数が導出されていった（詳細については文献 (4) (5)を 参照)。いっぽう, Zhouら ${ }^{(6)} や W o r t e l b o r e{ }^{(7)}$ は, 閉ルー プシステムの構造を維持したままコントローラの低次元化 を行う手法を提案した。彼らの手法では, 低次元化問題は 線形分数变換を利用して定式化されるため, 重みつき低次 元化問題も扱うことができる。

これらは, いずれも, 平衡化打ち切り法 ${ }^{(8)}$ を拡張した手 法である。その多くは, グラミアンのコントローラに対応 する一部分を平衡化 (同時対角化) し, 適当な状態変数を 打ち切る（取り除く）ことで低次元化を行う手法である。 しかし，グラミアン全体を平衡化するわけではないため, 平衡化打ち切り法にみられる有用な特性（考慮されたグラ ミアンに対応する状態変数が残ること, 誤差上界が容易に 得られることなど）を持たない。上記で挙げた手法の中で, Zhou らによって提案された手法（構造化平衡打ち切り法） は他の手法と異なり, グラミアンの一部分の代わりに，ブ ロック対角構造を持つ一般化グラミアンを平衡化すること で低次元化が行われる。一般化グラミアンは, リアプノフ 不等式の解であり, オリジナルの閉ループシステムを内包 
した拡大システム(これは一般化グラミアンの值によって 決定される）のグラミアンに一致する。したがって，一般 化グラミアンはグラミアンと同等の性質を有する（多少保 守的な）指標となる†。構造化平衡打ち切り法では, 構造が ブロック対角で固定された一般化グラミアンを活用するこ とにより，平衡化打ち切り法にみられるような有用な特性 を導くことができる。

本論文では, 構造化平衡打ち切り法を基礎として, ブロッ ク対角の一般化グラミアンを利用したコントローラ低次元 化法を提案する。しかしながら，閉ループ構造を持つ制御 システムに掠いては，ブロック対角の一般化グラミアンを 求めるためのリアプノフ不等式が可解でない場合が多い (6)。 この可解性の問題は，一般化グラミアンの構造をブロック 対角で固定することに起因する。そこで本提案手法では, この可解性の問題を解決するために，既約分解表現を用い て閉ループシステムを安定な既約因子の積で記述する。こ のように記述されたシステムにおいては，ブロック対角の 一般化グラミアンは常に存在するため, 可解性の問題が生 じない（このことは文献 (9)の成果によって示すことがで きる)。本提案手法では，このように記述された制御システ ムに対してブロック対角の一般化グラミアンを求める。こ こで，制御システムとそのサブシステムについて，コント ローラの低次元化によって生じる各サブシステム（制御シ ステム）の誤差ノルムは，コントローラ低次元化後の制御 システム (各サブシステム) の $\mathcal{H}_{\infty}$ 性能の上界を与えてい るという関倸が成り立つ。そこで，本提案手法では，低次 元化後の制御システム全体の $\mathcal{H}_{\infty}$ 性能に大きな影響を与 えるサブシステムを考慮するために，各サブシステムの一 般化グラミアンを組み合わせて平衡化し, 性能劣化の小さ な低次元化コントローラを求めること考える。また， 1 自 由度振動系および無人高機動航空機 $\mathrm{HIMAT}^{(10)}$ の $\mathcal{H}_{\infty}$ 制 御問題を数值例として用い, 提案手法の有効性を確認する。

最後に，本論文で扱う記号などについて言及しておく。 記号 $\mathcal{R} \mathcal{H}_{\infty}$ は安定プロパーな実有理伝達関数の集合を表 す。 $\operatorname{diag}(\cdot, \cdot)$ は対角行列またはブロック対角行列を表す。 演算 $\mathcal{F}_{l}(\cdot, \cdot)$ は下線形分数変換, $\operatorname{tr}(\cdot)$ はトレースを表す。 またノルム\|・列は $\mathcal{H}_{\infty}$ ノルムを表す。

\section{2. 構造化平衡打ち切り法}

図 1 の内部安定な閉ループシステムについて考える。同 図中に拈いて, $G$ は $m_{g}$ 次元の一般化プラント, $K$ は $m_{k}$ 次元のコントローラであり,これらを次式で与える。

$$
G=\left[\begin{array}{cc}
G_{z w} & G_{z} \\
G_{w} & G_{p}
\end{array}\right]=\left[\begin{array}{c|cc}
A_{g} & B_{g 1} & B_{g 2} \\
\hline C_{g 1} & D_{g 11} & D_{g 12} \\
C_{g 2} & D_{g 21} & D_{g 22}
\end{array}\right]
$$

†例えば，可観測グラミアンが入力がない場合の出力エネルギーを 与えるのに対し，一般化可観測グラミアンはその上界を与える。

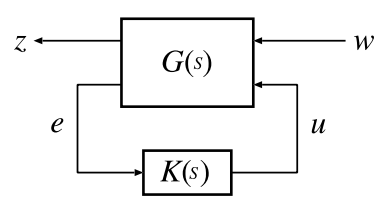

図 1 閉ループシステム

Fig. 1. Closed-loop system.

$$
K=\left[\begin{array}{c|c}
A_{k} & B_{k} \\
\hline C_{k} & D_{k}
\end{array}\right] \ldots \ldots \ldots \ldots \ldots \ldots \ldots \ldots \ldots
$$

このとき, $w$ から $z$ までの伝達関数 $T_{z w}$ は次式となる。

$$
\begin{aligned}
T_{z w} & =\mathcal{F}_{l}(G, K) \in \mathcal{R} \mathcal{H}_{\infty} \\
& =G_{z w}+G_{z} K\left(I-G_{p} K\right)^{-1} G_{w} \\
& =\left[\begin{array}{c|c}
A & B \\
\hline C & D
\end{array}\right] \ldots \ldots \ldots \ldots \ldots \ldots \ldots \ldots \ldots \ldots \ldots \\
A & =\left[\begin{array}{cc}
A_{g}+B_{g 2} L D_{k} C_{g 2} & B_{g 2} L C_{k} \\
B_{k} F C_{g 2} & A_{k}+B_{k} F D_{g 22} C_{k}
\end{array}\right] \\
B & =\left[\begin{array}{c}
B_{g 1}+B_{g 2} L D_{k} D_{g 21} \\
B_{k} F D_{g 21}
\end{array}\right] \\
C & =\left[\begin{array}{c}
C_{g 1}+D_{g 12} D_{k} F C_{g 2} \\
D_{g 12} L C_{k}
\end{array}\right] \\
D & =D_{g 11}+D_{g 12} D_{k} F D_{g 21} \\
L & =\left(I-D_{k} D_{g 22}\right)^{-1}, F=\left(I-D_{g 22} D_{k}\right)^{-1}
\end{aligned}
$$

次のリアプノフ不等式を満たすブロック対角の一般化可 制御グラミアン $\mathcal{P} ，$ 一般化可観測グラミアン $\mathcal{Q}$ を考える。

$$
\begin{array}{r}
A \mathcal{P}+\mathcal{P} A^{\mathrm{T}}+B B^{\mathrm{T}} \leq 0, \mathcal{P}=\operatorname{diag}\left(\mathcal{P}_{g}, \mathcal{P}_{k}\right) \geq 0 \\
\ldots \ldots \ldots \ldots \ldots \cdots \cdots \\
A^{\mathrm{T}} \mathcal{Q}+\mathcal{Q} A+C^{\mathrm{T}} C \leq 0, \mathcal{Q}=\operatorname{diag}\left(\mathcal{Q}_{g}, \mathcal{Q}_{k}\right) \geq 0
\end{array}
$$

ただし， $\mathcal{P}_{g}$ および $\mathcal{Q}_{g}$ は，一般化プラント $G$ に対応して おり, $m_{g} \times m_{g}$ 対称行列である。また, $\mathcal{P}_{k}$ および $\mathcal{Q}_{k}$ は, コントローラ $K$ に対応しており, $m_{k} \times m_{k}$ 対称行列であ る。このような $\mathcal{P}, \mathcal{Q}$ が存在するとき，下記の定理により， $\hat{m}_{k}$ 次の低次元化コントローラ $\hat{K}$ を求めることができる。 〔定理 1〕（Zhou ら ${ }^{(6)}$ ）（4）式および (5) の解である $\mathcal{P}$ および $\mathcal{Q}$ において, 次式を満足する平衡化（同時対 角化）行列 $\mathcal{T}$ が存在すると仮定する。

$$
\begin{aligned}
\mathcal{T}^{-1} \mathcal{P}_{k}\left(\mathcal{T}^{-1}\right)^{\mathrm{T}} & =\mathcal{T}^{\mathrm{T}} \mathcal{Q}_{k} \mathcal{T}=: \Sigma_{k} \cdots \cdots \cdots(6) \\
\Sigma_{k} & =\operatorname{diag}\left(\Sigma_{k 1}, \Sigma_{k 2}\right) \\
\Sigma_{k 1} & =\operatorname{diag}\left(\sigma_{1}, \cdots, \sigma_{\hat{m}_{k}}\right) \\
\Sigma_{k 2} & =\operatorname{diag}\left(\sigma_{\hat{m}_{k}+1}, \cdots, \sigma_{m_{k}}\right) \\
\sigma_{1} & \geq \cdots \geq \sigma_{\hat{m}_{k}}>\sigma_{\hat{m}_{k}+1} \geq \cdots \geq \sigma_{m_{k}}
\end{aligned}
$$

このとき, $\Sigma_{k}=\operatorname{diag}\left(\Sigma_{k 1}, \Sigma_{k 2}\right)$ に応じて分割された $K$ の構造化平衡実現は,

$$
K=\left[\begin{array}{c|c}
\mathcal{T}^{-1} A_{k} \mathcal{T} & \mathcal{T}^{-1} B_{k} \\
\hline C_{k} \mathcal{T} & D_{k}
\end{array}\right]
$$




$$
=:\left[\begin{array}{cc|c}
\hat{A}_{k} & \hat{A}_{k 12} & \hat{B}_{k} \\
\hat{A}_{k 21} & \hat{A}_{k 22} & \hat{B}_{k 2} \\
\hline \hat{C}_{k} & \hat{C}_{k 2} & D_{k}
\end{array}\right]
$$

となる。ここで， $\hat{K}$ を以下で定義する。

$$
\hat{K}=\left[\begin{array}{c|c}
\hat{A}_{k} & \hat{B}_{k} \\
\hline \hat{C}_{k} & D_{k}
\end{array}\right]
$$

この $\hat{K}$ により構成される制御システム $\hat{T}_{z w}$ は,

$$
\hat{T}_{z w}=\mathcal{F}_{l}(G, \hat{K}) \in \mathcal{R} \mathcal{H}_{\infty}
$$

$$
\begin{aligned}
& =G_{z w}+G_{z} \hat{K}\left(I-G_{p} \hat{K}\right)^{-1} G_{w} \\
& =:\left[\begin{array}{l|l}
\hat{A} & \hat{B} \\
\hline \hat{C} & D
\end{array}\right] \text {. }
\end{aligned}
$$

となる。また， $\hat{T}_{z w}$ と $T_{z w}$ に関して次式が成り立つ。

$$
\left\|\hat{T}_{z w}-T_{z w}\right\|_{\infty} \leq 2 \operatorname{tr}\left(\Sigma_{k 2}\right)
$$

定理 1 は，下記の一般化グラミアンの性質を利用して証明 される（詳細については文献 (6) を参照)。

〔性質 1〕（打ち切りシステムの一般化グラミアン）

式，(5) および (6) で求めた $\mathcal{P}_{g}, \mathcal{Q}_{g}$ および $\Sigma_{k 1}$ を用い て, $\hat{\mathcal{P}}$ と $\hat{\mathcal{Q}}$

$$
\begin{aligned}
& \hat{\mathcal{P}}=\operatorname{diag}\left(\mathcal{P}_{g}, \Sigma_{k 1}\right) \\
& \hat{\mathcal{Q}}=\operatorname{diag}\left(\mathcal{Q}_{g}, \Sigma_{k 1}\right)
\end{aligned}
$$

で与えると，次式が成り立つ。

$$
\begin{aligned}
& \hat{A} \hat{\mathcal{P}}+\hat{\mathcal{P}} \hat{A}^{\mathrm{T}}+\hat{B} \hat{B}^{\mathrm{T}} \leq 0 \\
& \hat{A}^{\mathrm{T}} \hat{\mathcal{Q}}+\hat{\mathcal{Q}} \hat{A}+\hat{C}^{\mathrm{T}} \hat{C} \leq 0
\end{aligned}
$$

ただし，低次元化の過程において $G$ 抢よび $\hat{K}$ の状態変 換は行われていないものとする。

〔性質 2〕（一般化グラミアンとグラミアンの関係） 次の 準正定行列 $E_{b}$ および $E_{c}$ について考える。

$$
\begin{aligned}
& E_{b}=-\left(A \mathcal{P}+\mathcal{P} A^{\mathrm{T}}+B B^{\mathrm{T}}\right) \geq 0 \cdots \cdots \cdots \\
& E_{c}=-\left(A^{\mathrm{T}} \mathcal{Q}+\mathcal{Q} A+C^{\mathrm{T}} C\right) \geq 0 \cdots \cdots \cdots
\end{aligned}
$$

このとき，(4) 式 および (5) より，次式が成り立つ。

$$
\begin{array}{r}
A \mathcal{P}+\mathcal{P} A^{\mathrm{T}}+\left[\begin{array}{ll}
B & E_{b}^{\frac{1}{2}}
\end{array}\right]\left[\begin{array}{c}
B^{\mathrm{T}} \\
E_{b}^{\frac{1}{2}}
\end{array}\right]=0 \\
\ldots \ldots \ldots \ldots \ldots \ldots \\
A^{\mathrm{T}} \mathcal{Q}+\mathcal{Q} A+\left[\begin{array}{ll}
C^{\mathrm{T}} & E_{c}^{\frac{1}{2}}
\end{array}\right]\left[\begin{array}{c}
C \\
E_{c}^{\frac{1}{2}}
\end{array}\right]=0
\end{array}
$$

これは，P拈よび $\mathcal{Q}$ が次の拡大制御システム $H$ の可 制御および可観測グラミアンとなることを示している。

$$
H=\left[\begin{array}{c|cc}
A & B & E_{b}^{\frac{1}{2}} \\
\hline C & D & 0 \\
E_{c}^{\frac{1}{2}} & 0 & 0
\end{array}\right] \in \mathcal{R H}_{\infty}
$$

ここで，次の制御システム $\tilde{T}_{z w}$ を導入する。

$$
\tilde{T}_{z w}=\left[\begin{array}{c|c}
A & E_{b}^{\frac{1}{2}} \\
\hline E_{c}^{\frac{1}{2}} & 0
\end{array}\right] \in \mathcal{R} \mathcal{H}_{\infty}
$$

制御システム $T_{z w}$ 抢よび $\tilde{T}_{z w}$ の可制御グラミアンを,

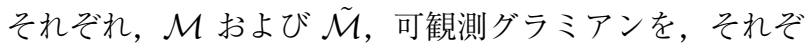

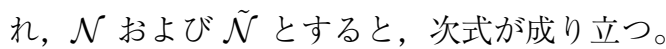

$$
\begin{array}{r}
A(\mathcal{M}+\tilde{\mathcal{M}})+(\mathcal{M}+\tilde{\mathcal{M}}) A^{\mathrm{T}}+B B^{\mathrm{T}}+E_{b}=0 \\
\ldots \ldots \ldots \ldots \cdots \cdots \\
A^{\mathrm{T}}(\mathcal{N}+\mathcal{N})+(\mathcal{N}+\tilde{\mathcal{N}}) A+C^{\mathrm{T}} C+E_{c}=0
\end{array}
$$

これより以下が得られる。

$$
\begin{aligned}
& \mathcal{P}=\mathcal{M}+\tilde{\mathcal{M}} . \\
& \mathcal{Q}=\mathcal{N}+\tilde{\mathcal{N}} \cdots
\end{aligned}
$$

性質 1 は,「个命が安定行列である, すなわち, 打ち切りシス テム $\hat{T}_{z w}$ が安定である」ということを示しており，性質 $\mathbf{2}$ は,「P と $\mathcal{Q}$ を平衡化して $T_{z w}$ の状態変数を打ち切ること は， $H$ に対し平衡化打ち切り法を適用することと等価であ る」ということを示している。これにより，(10) 式拈よび (11) が導かれる。このように, ブロック対角の一般化グラ ミアンを活用することによって, 構造化平衡打ち切り法で は, 打ち切りシステム $\hat{T}_{z w}$ の安定性が保証され, また, 誤 差上界により制御性能の劣化が制限される。

これらの特性は非常に有用であるが，この手法の欠点と して, リアプノフ不等式 (4) および (5) の可解性の問題が ある。(4) 式（(5) 式）から確認できるように，ブロック対 角の一般化可制御グラミアン P (一般化可制御グラミアン Q） が存在するためには, $T_{z w}$ の係数行列 $A$ のブロック 対角要素 $A_{g}+B_{g 2} L D_{k} C_{g 2}$ および $A_{k}+B_{k} F D_{g 22} C_{k}$ が 安定である必要がある。この問題は，一般化グラミアンの 構造をブロック対角で固定することに起因しており, 多く のコントローラ低次元化問題において生じる。しかし， $G$ が特別な構造を持つ場合には, リアプノフ不等式が可解と なり, ブロック対角の一般化グラミアンが常に存在するこ とが知られている。以下はこれに関する定理である。

〔定理 2〕（Oh ら $\left.{ }^{(9)}\right) \quad G$ が次式で与えられていると仮 定する。

$$
G=\left[\begin{array}{cc}
0 & W_{z} \\
W_{w} & 0
\end{array}\right], \quad W_{z}, W_{w} \in \mathcal{R H}_{\infty}
$$

$K \in \mathcal{R H}_{\infty}$ のとき, $T_{z w}=\mathcal{F}_{l}(G, K)$ は次式となる。

$$
T_{z w}=W_{z} K W_{w} \in \mathcal{R} \mathcal{H}_{\infty} \cdots \ldots \ldots \ldots \ldots(27)
$$

このシステムに扔いて，ブロック対角の一般化グラミア ン $\mathcal{P}$ および $\mathcal{Q}$ は常に存在する。

定理 2 は, 重みつき低次元化問題に帰着されたコントロー ラの低次元化問題（このとき $W_{z}$ および $W_{w}$ は閉ループ 特性を考慮するために導入される重み関数となる）におい て有用である。また，定理 2 から，より一般的な以下の結 果が得られる。

〔系 1〕 $G$ が次式で与えられていると仮定する。

$$
G=\left[\begin{array}{cc}
W_{z w} & W_{z} \\
W_{w} & 0
\end{array}\right], \quad W_{z w}, W_{z}, W_{w} \in \mathcal{R} \mathcal{H}_{\infty}
$$

$K \in \mathcal{R H}_{\infty}$ のとき， $T_{z w}=\mathcal{F}_{l}(G, K)$ は次式となる。

$$
T_{z w}=W_{z w}+W_{z} K W_{w} \in \mathcal{R} \mathcal{H}_{\infty}
$$


このシステムにおいて, ブロック対角の一般化グラミア ン $\mathcal{P}$ および $\mathcal{Q}$ は常に存在する。

〔証明〕 $W_{z w}$ の一般化グラミアンと $W_{z} K W_{w}$ のブロッ ク対角の一般化グラミアンは独立して求めることができ るので，定理 2 より明らかである。

\section{3. 既約分解による制御システムの表現}

図 2 の標準的なフィードバックシステムを考える。Pは プラント，Kはコントローラであり，この制御システムは 内部安定であるとする。また, この制御システムでは, ref は目標值入力, $d_{u}$ は $P$ の入力側の外部入力 (外乱や摂動 入力), $d_{y}$ は $P$ の出力側の外部入力, $n$ は雑音入力を想定 しており， $u$ は制御入力, $y$ は測定出力, $e$ は偏差となる。 ここで, $z$ と $w$ を

$$
z=\left[\begin{array}{l}
z_{1} \\
z_{2}
\end{array}\right]=\left[\begin{array}{l}
u \\
y
\end{array}\right], w=\left[\begin{array}{l}
w_{1} \\
w_{2} \\
w_{3}
\end{array}\right]=\left[\begin{array}{c}
d_{u} \\
d_{y} \\
r e f-n
\end{array}\right]
$$

で与え†，この制御システムを図 1 のように一般化する。こ のときの一般化プラント $G$ を

$$
\begin{gathered}
G=\left[\begin{array}{rrr:r}
G_{z_{1} w_{1}} & G_{z_{1} w_{2}} & G_{z_{1} w_{3}} & G_{z_{1}} \\
G_{z_{2} w_{1}} & G_{z_{2} w_{2}} & G_{z_{2} w_{3}} & G_{z_{2}} \\
\hdashline G_{w_{1}} & G_{w_{2}} & G_{w_{3}} & G_{p}
\end{array}\right] \ldots \ldots \ldots \ldots \ldots \ldots(31) \\
\ldots \ldots \ldots \ldots \ldots \ldots \\
{\left[\begin{array}{c}
z_{1} \\
z_{2} \\
e
\end{array}\right]=\left[\begin{array}{ccc:c}
G_{z_{1} w_{1}} & G_{z_{1} w_{2}} & G_{z_{1} w_{3}} & G_{z_{1}} \\
G_{z_{2} w_{1}} & G_{z_{2} w_{2}} & G_{z_{2} w_{3}} & G_{z_{2}} \\
\hdashline G_{w_{1}} & G_{w_{2}} & G_{w_{3}} & G_{p}
\end{array}\right]\left[\begin{array}{c}
w_{1} \\
w_{2} \\
w_{3} \\
\hdashline u
\end{array}\right]}
\end{gathered}
$$

で与えると, $w$ から $z$ までの伝達関数 $T_{z w}$ は,

$$
\begin{gathered}
T_{z w}=\left[\begin{array}{lll}
T_{z_{1} w_{1}} & T_{z_{1} w_{2}} & T_{z_{1} w_{3}} \\
T_{z_{2} w_{1}} & T_{z_{2} w_{2}} & T_{z_{2} w_{3}}
\end{array}\right] \in \mathcal{R H}_{\infty} \cdots \\
T_{z_{i} w_{j}}=G_{z_{i} w_{j}}+G_{z_{i}} K\left(I-G_{p} K\right)^{-1} G_{w_{j}} \cdots
\end{gathered}
$$

となる。ただし， $T_{z_{i} w_{j}}(i=1,2, j=1,2,3)$ は, $w_{j}$ か ら $z_{i}$ までの伝達関数を表す。ここで, $G_{p}(=-P)$ と $K$ の $\mathcal{R H}_{\infty}$ 上での既約分解を考える。

$$
\begin{aligned}
& G_{p}=U_{r} V_{r}^{-1}=V_{l}^{-1} U_{l} \\
& U_{r}, U_{l}, V_{r}, V_{l} \in \mathcal{R} \mathcal{H}_{\infty} \\
& K=X_{r} Y_{r}^{-1}=Y_{l}^{-1} X_{l} \cdots \\
& X_{r}, X_{l}, Y_{r}, Y_{l} \in \mathcal{R} \mathcal{H}_{\infty}
\end{aligned}
$$

ただし，上式の既約分解において，以下の等式（ダブルベ ズー等式）が成り立つと仮定する。

$$
\left[\begin{array}{cc}
V_{l} & -U_{l} \\
X_{l} & Y_{l}
\end{array}\right]\left[\begin{array}{cc}
Y_{r} & U_{r} \\
-X_{r} & V_{r}
\end{array}\right]=\left[\begin{array}{ll}
I & 0 \\
0 & I
\end{array}\right]
$$

†図 2 では, ref から各出力までの伝達関数と $-n$ から各出力まで の伝達関数は等しくなるので, $w_{3}=r e f-n$ とまとめて記述する。

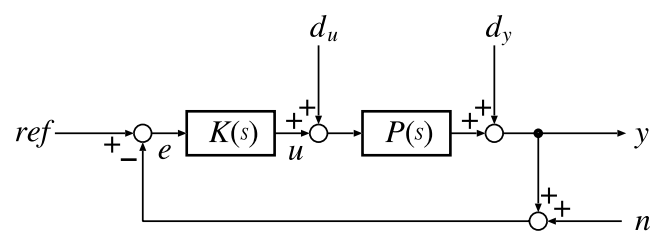

図 2 標準的なフィードバックシステムの構成

Fig. 2. Standard feedback configuration.

(34) （36) 式より，各サブシステム $T_{z_{i} w_{j}}$ は，

$$
\begin{aligned}
T_{z_{i} w_{j}} & =G_{z_{i} w_{j}}+G_{z_{i}} X_{r} V_{l} G_{w_{j}} \\
& =\mathcal{F}_{l}\left(G_{i j}^{r \prime}, S_{i j}^{r \prime}\right)=: T_{i j}^{r \prime} \ldots \ldots \ldots \ldots \\
G_{i j}^{r \prime} & =\left[\begin{array}{cc}
G_{z_{i} w_{j}} & G_{z_{i}} \\
V_{l} G_{w_{j}} & 0
\end{array}\right], \quad S_{i j}^{r \prime}=X_{r}
\end{aligned}
$$

または，

$$
\begin{aligned}
& T_{z_{i} w_{j}}=G_{z_{i} w_{j}}+G_{z_{i}} V_{r} X_{l} G_{w_{j}} \\
& =\mathcal{F}_{l}\left(G_{i j}{ }^{\prime}{ }^{\prime}, S_{i j}^{l}{ }^{\prime}\right)=: T_{i j}{ }^{\prime}{ }^{\prime} \\
& G_{i j}{ }^{\prime}{ }^{\prime}=\left[\begin{array}{cc}
G_{z_{i} w_{j}} & G_{z_{i}} V_{r} \\
G_{w_{j}} & 0
\end{array}\right], \quad S_{i j}^{l}{ }^{\prime}=X_{l}
\end{aligned}
$$

と書くことができるけ†。これからわかるように，各サブシ ステム $T_{z_{i} w_{j}}$ は， $G_{p}$ の左既約因子と $K$ の右既約因子, ま たは， $G_{p}$ の右既約因子 と $K$ の左既約因子の積で構成さ れる二通りの伝達関数によって記述することができる。

〔注釈 1〕 サブシステムによっては，(37) 式㧍よび (38) が最小実現にならない場合があることに注意する。例え ば，図 2 のサブシステム $T_{z_{2} w_{2}}=T_{y d_{y}}$ (感度関数) を考 える。このとき，(37)式は，

$$
\begin{aligned}
T_{22}^{r \prime} & =\mathcal{F}_{l}\left(G_{22}^{r}{ }^{\prime}, S_{22}^{r}{ }^{\prime}\right) \\
& =I-P X_{r} V_{l} \\
& =Y_{r} V_{l}=\mathcal{F}_{l}\left(G_{22}^{r}, S_{22}^{r}\right)=: T_{22}^{r} \\
G_{22}^{r} & =\left[\begin{array}{cc}
0 & I \\
V_{l} & 0
\end{array}\right], \quad S_{22}^{r}=Y_{r}
\end{aligned}
$$

と変形することができる。これからわかるように， $T_{22}^{r}{ }^{\prime}$ と $T_{22}^{r}$ は等価であるが, $G_{22}^{r}$ の次数は $G_{22}^{r}$ の次数より 高くなる。ここで, $f=r, l$ として, (37) 式および (38) を(39) 式のように適宜 $T_{i j}^{f}$ として変形し, 次の最小実 現の形式で書くことにする。

$$
T_{i j}^{f}=\mathcal{F}_{l}\left(G_{i j}^{f}, S_{i j}^{f}\right)
$$

\section{4. 一般化グラミアンの組合せによるコントローラ の低次元化}

高次元コントローラの低次元化を考えるとき，その低次 元化コントローラは, 一般に, ある評価によって順番づけ られた状態変数を打ち切ることで求められる。前述した構 造化平衡打ち切り法では, ブロック対角の一般化グラミア

${ }_{\dagger \dagger} T_{i j}^{r \prime}\left(T_{i j}^{l}{ }^{\prime}\right)$ の上付き添字 $r(l)$ は，Kの右既約因子（左既約因 子）を使って各サブシステムが記述されていることを示す。 
ンの平衡化によって状態変数の制御システム全体における 重要度（これは $\Sigma_{k}$ の対角要素の大きさによって表されて おり, その值が小さいほど重要度が低い) を測り, その重 要度の低い状態变数を打ち切ることで低次元化を行ってい る。また，この手法では (11) 式によって誤差上界が与えら れるので, 得られた低次元化コントローラ $\hat{K}$ で構成され る制御システム $\hat{T}_{z w}$ の $\mathcal{H}_{\infty}$ ノルムについて，以下の関係 が得られる。

$$
\begin{aligned}
\left\|\hat{T}_{z w}\right\|_{\infty} & \leq\left\|\hat{T}_{z w}-T_{z w}\right\|_{\infty}+\left\|T_{z w}\right\|_{\infty} \\
& \leq 2 \operatorname{tr}\left(\Sigma_{k 2}\right)+\left\|T_{z w}\right\|_{\infty} \cdots \cdots
\end{aligned}
$$

コントローラの設計方法の違いによって構造化平衡打ち切 り法の適用が制限されることはないが，この関係から，特 に, $\mathcal{H}_{\infty}$ ノルムを設計指標としたコントローラ $\left(\mathcal{H}_{\infty}\right.$ コン トローラなど）の低次元化に対して有効であることがわか る。また，一般化グラミアンの性質 1 で示したように，コ ントローラ低次元化後の制御システム $\hat{T}_{z w}$ は，一般化グラ ミアンとして (12) 式拉よび (13) を持つ。これらは平衡化 された $T_{z w}$ の一般化グラミアンの一部分となっており, こ れらに対応する状態変数（すなわち，打ち切りに执いて残 された重要度の高い状態变数）を持つ $\hat{T}_{z w}$ の $\mathcal{H}_{\infty}$ 性能の 劣化は，(41) 式によって制限されていると考えることがで きる。ここで，(41) 式の関係についてさらに詳しく調べて みる。制御システム $T_{z w}$ とそのサブシステム $T_{z_{i} w_{j}}$ の関 係より，以下が成り立つ。

$$
\begin{aligned}
& \left\|\hat{T}_{z w}\right\|_{\infty} \leq 2 \operatorname{tr}\left(\Sigma_{k 2}\right)+\left\|T_{z w}\right\|_{\infty} \\
& \Rightarrow\left\|\hat{T}_{z_{i} w_{j}}\right\|_{\infty} \leq 2 \operatorname{tr}\left(\Sigma_{k 2}\right)+\left\|T_{z w}\right\|_{\infty} \cdots \cdots \cdots(42) \\
& \sum_{i, j}\left\|\hat{T}_{z_{i} w_{j}}\right\|_{\infty} \leq \sum_{i, j}\left(\left\|\hat{T}_{z_{i} w_{j}}-T_{z_{i} w_{j}}\right\|_{\infty}+\left\|T_{z_{i} w_{j}}\right\|_{\infty}\right) \\
& \Rightarrow\left\|\hat{T}_{z w}\right\|_{\infty} \leq \sum_{i, j}\left(\left\|\hat{T}_{z_{i} w_{j}}-T_{z_{i} w_{j}}\right\|_{\infty}+\left\|T_{z_{i} w_{j}}\right\|_{\infty}\right)
\end{aligned}
$$

$$
\hat{T}_{z_{i} w_{j}}=G_{z_{i} w_{j}}+G_{z_{i}} \hat{K}\left(I-G_{p} \hat{K}\right)^{-1} G_{w_{j}}
$$

この関係から, $\left\|\hat{T}_{z w}\right\|_{\infty}$ と $\left\|\hat{T}_{z_{i} w_{j}}\right\|_{\infty}$ の值は, 互いの誤差 ノルムによって制限されていることがわかる。また，各サ ブシステムの誤差ノルム $\left\|\hat{T}_{z_{i} w_{j}}-T_{z_{i} w_{j}}\right\|_{\infty}$ がコントロー ラ低次元後の制御システム全体の $\mathcal{H}_{\infty}$ 性能 $\left\|\hat{T}_{z w}\right\|_{\infty}$ に与 える影響度はそれぞれ異なるので, 影響度の高いサブシス テムの誤差ノルムを優先して小さくすることにより，制御 システム全体の $\mathcal{H}_{\infty}$ 性能の劣化を抑えることができると 考えられる。上で述べたように，平衡化した一般化攵ラミ アンによって評価づけされた重要度の高い状態変数は，コ ントローラ低次元後に打いても残り，その残った状態変数 によってコントローラ低次元化後の制御システム $\hat{T}_{z w}$ の 特性が決定される。この性質を利用して， $\hat{T}_{z w}$ の $\mathcal{H}_{\infty}$ 性 能に大きな影響を与えるサブシステムの状態変数を選択す る（打ち切りに扔いて残す）ために，各サブシステムの一 般化グラミアンを組合せて平衡化することを考える。ここ
では，そのすべての組合せに対して低次元化コントローラ を求め, 性能劣化の最も小さいものを最終的な低次元化コ ントローラとして選ぶ。なお， 2 章で述べたように，フィー ドバック構造を持つ制御システムにおいてはリアプノフ不 等式の可解性に問題があるので，本提案手法では，既約分 解を用いて記述された (40) 式の制御システムに対して一般 化グラミアンを求める。このように記述された制御システ ムに扔いては，系 1 によってブロック対角の一般化グラミ アンの存在が保証されており，コントローラ $K$ の既約因 子 $S_{i j}^{f}$ が低次元化の対象となる。

以上をまとめて，本論文では，次のコントローラ低次元 化アルゴリズムを提案する。

\section{【提案アルゴリズム】}

Step 1 （制御システムの表現）ダブルベズー等 (36) 式 を満足する $G_{p}$ と $K$ の既約因子を用いて，(40) 式のよ うに記述された各サブシステム $T_{i j}^{f}$ を求める。ここで, $T_{i j}^{f}$ の実現を以下で与える。

$$
T_{i j}^{f}=\mathcal{F}_{l}\left(G_{i j}^{f}, S_{i j}^{f}\right)=\left[\begin{array}{c|c}
A_{i j}^{f} & B_{i j}^{f} \\
\hline C_{i j}^{f} & D_{i j}^{f}
\end{array}\right]
$$

Step 2 (一般化グラミアンの計算) 各 $T_{i j}^{f}$ において, 以下のリアプノフ不等式を解く。

$$
\begin{aligned}
& A_{i j}^{f} \mathcal{P}+\mathcal{P} A_{i j}^{f^{\mathrm{T}}}+B_{i j}^{f} B_{i j}^{f^{\mathrm{T}}} \leq 0, \mathcal{P}=\operatorname{diag}\left(\mathcal{P}_{g}, \mathcal{P}_{k}\right) \geq 0 \\
& A_{i j}^{f \mathrm{~T}} \mathcal{Q}+\mathcal{Q} A_{i j}^{f}+C_{i j}^{f \mathrm{~T}} C_{i j}^{f} \leq 0, \mathcal{Q}=\operatorname{diag}\left(\mathcal{Q}_{g}, \mathcal{Q}_{k}\right) \geq 0
\end{aligned}
$$
ここで, $\mathcal{P}_{g}$ および $\mathcal{Q}_{g}$ は $G_{i j}^{f}$ に対応し, $\mathcal{P}_{k}$ および $\mathcal{Q}_{k}$ は $S_{i j}^{f}$ に対応する。便宜上, 求めた各一般化可制御グラ ミアンを $\mathcal{P}\left\{T_{i j}^{f}\right\}$, 各一般化可観測グラミアンを $\mathcal{Q}\left\{T_{i j}^{f}\right\}$ と表記する。

Step 3 （コントローラの低次元化） 平衡化する一般化 グラミアンの組合せを $\left(\mathcal{P}\left\{T_{i_{1} j_{1}}^{f_{1}}\right\}, \mathcal{Q}\left\{T_{i_{2} j_{2}}^{f_{2}}\right\}\right)_{b}$ と表記 し，この組合せにより得られた低次元化コントローラを $\hat{K}\left[\left(\mathcal{P}\left\{T_{i_{1} j_{1}}^{f_{1}}\right\}, \mathcal{Q}\left\{T_{i_{2} j_{2}}^{f_{2}}\right\}\right)_{b}\right]$ と書く。ここで, $i_{1}\left(i_{2}\right), j_{1}$ $\left(j_{2}\right)$ および $f_{1}\left(f_{2}\right)$ は, それぞれ, $i, j$ および $f$ と同 じ值をとる。全ての組合せに対して低次元化コントロー ラを求め, その中で性能劣化の最も小さいものを最終的 な低次元化コントローラ $\hat{K}_{o p t}$ として選ぶ。すなわち,

$$
\begin{aligned}
& \left\|\mathcal{F}_{l}\left(G, \hat{K}_{\text {opt }}\right)\right\|_{\infty}= \\
& \min _{\left(i_{1}, j_{1}, f_{1}\right),\left(i_{2}, j_{2}, f_{2}\right)}\left\|\mathcal{F}_{l}\left(G, \hat{K}\left[\left(\mathcal{P}\left\{T_{i_{1} j_{1}}^{f_{1}}\right\}, \mathcal{Q}\left\{T_{i_{2} j_{2}}^{f_{2}}\right\}\right) b\right]\right)\right\|_{\infty}
\end{aligned}
$$

なる低次元化コントローラ $\hat{K}_{o p t}$ を求める。

〔注釈 2〕各サブシステム $T_{i j}^{f}$ に関して, 同じサブシ ステムの一般化グラミアンを平衡化した場合（例えば $\left(\mathcal{P}\left\{T_{11}^{r}\right\}, \mathcal{Q}\left\{T_{11}^{r}\right\}\right)_{b}$ のように) は，(11) 式より上界を 求めることができるが，異なるサブシステムの一般化グ ラミアンを平衡化した場合（例えば $\left(\mathcal{P}\left\{T_{12}^{r}\right\}, \mathcal{Q}\left\{T_{22}^{l}\right\}\right)_{b}$ のように）は，(11)式の関係を利用することができない。 これは，もう一方の一般化グラミアン（上の例では，平 衡化された一般化制御グラミアン $\mathcal{P}\left\{T_{12}^{r}\right\}$ に対して同じ サブシステム $T_{12}^{r}$ の一般化可観測グラミアン $\mathcal{Q}\left\{T_{12}^{r}\right\}$, 
また，平衡化された一般化可観測グラミアン $\mathcal{Q}\left\{T_{22}^{l}\right\}$ に 対して同じサブシステム $T_{22}^{l}$ の一般化可観測グラミアン $\mathcal{P}\left\{T_{22}^{l}\right\}$ に当たる) が平衡化されていないためである。し かしながら，平衡化されていないもう一方の一般化攵ラ ミアンの影響が小さい場合には, 誤差上界を得ることが できる。次の定理はこれについて示したものである。

〔定理 3〕 $T_{i_{1} j_{1}}^{f_{1}} \in \mathcal{R} \mathcal{H}_{\infty}$ の一般化可制御グラミアン $\mathcal{P}\left\{T_{i_{1} j_{1}}^{f_{1}}\right\}$ と $T_{i_{2} j_{2}}^{f_{2}} \in \mathcal{R} \mathcal{H}_{\infty}$ の一般化可観測グラミア ン $\mathcal{Q}\left\{T_{i_{2} j_{2}}^{f_{2}}\right\} \quad\left(i_{1} \neq i_{2}, j_{1} \neq j_{2}\right.$ and/or $\left.f_{1} \neq f_{2}\right)$ が平 衡であると仮定する。

$$
\begin{aligned}
\mathcal{P}\left\{T_{i_{1} j_{1}}^{f_{1}}\right\} & =\operatorname{diag}\left(\mathcal{P}_{g}, \Sigma_{k}\right) \cdots \ldots \ldots \ldots \ldots \ldots \\
\mathcal{Q}\left\{T_{i_{2} j_{2}}^{f_{2}}\right\} & =\operatorname{diag}\left(\mathcal{Q}_{g}, \Sigma_{k}\right) \ldots \ldots \ldots \ldots \ldots \ldots \\
\Sigma_{k} & =\operatorname{diag}\left(\Sigma_{k 1}, \Sigma_{k 2}\right) \\
\Sigma_{k 1} & =\operatorname{diag}\left(\sigma_{1}, \cdots, \sigma_{\hat{m}_{k}}\right) \\
\Sigma_{k 2} & =\operatorname{diag}\left(\sigma_{\hat{m}_{k}+1}, \cdots, \sigma_{m_{k}}\right) \\
\sigma_{1} & \geq \cdots \geq \sigma_{\hat{m}_{k}}>\sigma_{\hat{m}_{k}+1} \geq \cdots \geq \sigma_{m_{k}}
\end{aligned}
$$

$T_{i_{1} j_{1}}^{f_{1}}$ の一般化可観測グラミアン $\mathcal{Q}\left\{T_{i_{1} j_{1}}^{f_{1}}\right\}$ について, $\mathcal{P}\left\{T_{i_{1} j_{1}}^{f_{1}}\right\} \geq \mathcal{Q}\left\{T_{i_{1} j_{1}}^{f_{1}}\right\}$ のとき, 次式が成り立つ。

$$
\left\|\hat{T}_{i_{1} j_{1}}^{f_{1}}-T_{i_{1} j_{1}}^{f_{1}}\right\|_{\infty} \leq 2 \operatorname{tr}\left(\Sigma_{k 2}\right)
$$

同様に, $T_{i_{2} j_{2}}^{f_{2}}$ の一般化可制御グラミアン $\mathcal{P}\left\{T_{i_{2} j_{2}}^{f_{2}}\right\}$ につ いて, $\mathcal{Q}\left\{T_{i_{2} j_{2}}^{f_{2}}\right\} \geq \mathcal{P}\left\{T_{i_{2} j_{2}}^{f_{2}}\right\}$ とき, 次式が成り立つ。

$$
\left\|\hat{T}_{i_{2} j_{2}}^{f_{2}}-T_{i_{2} j_{2}}^{f_{2}}\right\|_{\infty} \leq 2 \operatorname{tr}\left(\Sigma_{k 2}\right) \cdots
$$

ただし， $\hat{T}_{i_{1} j_{1}}^{f_{1}}\left(\hat{T}_{i_{2} j_{2}}^{f_{2}}\right)$ は低次元化既約因子 $\hat{S}_{i_{1} j_{1}}^{f_{1}}\left(\hat{S}_{i_{2} j_{2}}^{f_{2}}\right)$ で構成されたサブシステムである。

〔証明〕サブシステム $T_{i_{1} j_{1}}^{f_{1}}$ の実現を以下で与える。

$$
T_{i_{1} j_{1}}^{f_{1}}=\left[\begin{array}{c|c}
A_{*} & B_{*} \\
\hline C_{*} & D_{*}
\end{array}\right]
$$

$\mathcal{Q}\left\{T_{i_{1} j_{1}}^{f_{1}}\right\}$ は $T_{i_{1} j_{1}}^{f_{1}}$ の一般化可観測グラミアンであるので,

$$
C_{*}{ }^{\mathrm{T}} C_{*} \leq-\left(A_{*}{ }^{\mathrm{T}} \mathcal{Q}\left\{T_{i_{1} j_{1}}^{f_{1}}\right\}+\mathcal{Q}\left\{T_{i_{1} j_{1}}^{f_{1}}\right\} A_{*}\right)
$$

が成り立つ。 $\Delta:=\mathcal{P}\left\{T_{i_{1} j_{1}}^{f_{1}}\right\}-\mathcal{Q}\left\{T_{i_{1} j_{1}}^{f_{1}}\right\} \geq 0$ より，

$$
\begin{aligned}
A_{*}{ }^{\mathrm{T}} \mathcal{P}\left\{T_{i_{1} j_{1}}^{f_{1}}\right\} & +\mathcal{P}\left\{T_{i_{1} j_{1}}^{f_{1}}\right\} A_{*}+C_{*}^{\mathrm{T}} C_{*} \\
& \leq A_{*}{ }^{\mathrm{T}} \Delta+\Delta A_{*} \leq 0 \cdots \cdots
\end{aligned}
$$

となるので, $\mathcal{P}\left\{T_{i_{1} j_{1}}^{f_{1}}\right\}$ はサブシステム $T_{i_{1} j_{1}}^{f_{1}}$ の一般化可 観測グラミアンでもある。したがって，定理 1 より，サ ブシステム $T_{i_{1} j_{1}}^{f_{1}}$ の $\Sigma_{k 2}$ に対応する状態変数を打ち切る ことで (46) 式を得る。(47) 式も同様に導かれる。

〔注釈 3〕 コントローラの既約因子の低次元化について 言及しておく。コントローラ $K$ の右既約因子 $X_{r}$ と $Y_{r}$ (左既約因子 $X_{l}$ と $Y_{l}$ ) に共通のユニモジュラ行列が含ま れない場合，それらの次数はコントローラ $K$ の次数に等 しい。したがって，このような既約因子を低次元化するこ とで低次元化コントローラを求めることができる。いま， 既約因子がその平衡化行列 $\mathcal{T} に よ っ て$ 低次元化された場 合を考える。低次元化された既約因子を $\hat{X}_{r}, \hat{Y}_{r}\left(\hat{X}_{l}, \hat{Y}_{l}\right)$

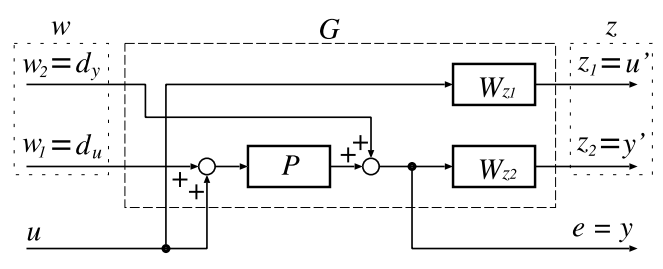

困 3 例題 1 および 2 の一般化プラント

Fig. 3. Generalized plant for examples.

とおくと, 低次元化コントローラ $\hat{K}$ は, $\hat{K}=\hat{X}_{r} \hat{Y}_{r}^{-1}$ $\left(\hat{K}=\hat{Y}_{l}^{-1} \hat{X}_{l}\right)$ で構成される。また, $\mathcal{T}$ を直接 $K$ に 適用して低次元化を行っても $\hat{K}$ が得られることが知ら れている(11)。本提案手法に扔いては，例えば，図 2 の 感度関数の右既既約因子表現 $T_{22}^{r}$ の一般化グラミアンを 平衡化した場合を考えたとき， $K$ の低次元化既約因子は $\hat{S}_{22}^{r}=\hat{Y}_{r}$ のみが求まる。したがって, $\hat{K}=\hat{X}_{r} \hat{Y}_{r}^{-1}$ と いうように低次元化コントローラを求めることはできな いが，得られた平衡化行列 $\mathcal{T}$ を(8) 式のように直接 $K$ に適用して $\hat{K}$ を求めることができる。

\section{5. 数 值 例}

本節では， 1 自由度振動系および無人高機動航空機 HI$\mathrm{MAT}^{(10)}$ の $\mathcal{H}_{\infty}$ 制御問題を用いて, 提案法の有効性を確 認する。ここでは, $\mathcal{H}_{\infty}$ 中心解コントローラ $K$ を設計し, これを低次元化することを考える。制御システムの $\mathcal{H}_{\infty}$ ノ ルムが設定值 $\gamma$ 未満となる $\mathcal{H}_{\infty}$ コントローラには自由度 があり, 中心解コントローラはその中核的な存在となる。こ の自由度をパラメータ $Q$ で表現した場合, 一般的な $\mathcal{H}_{\infty}$ コントローラ $K_{g}$ は,

$$
K_{g}=\mathcal{F}_{l}\left(M_{\infty}, Q\right), \quad Q \in \mathcal{R} \mathcal{H}_{\infty}^{l_{u} \times l_{e}}, \quad\|Q\|_{\infty}<\gamma
$$

で与えられる ${ }^{(4)}$ 。ここで， $M_{\infty}$ は問題とする一般化プラン 卜および設定值 $\gamma$ で決定される伝達関数であり， $l_{u}$ 拉よ び $l_{e}$ は $K_{g}$ の入力数拉よび出力数である。 $M_{\infty}$ の実現を

$$
M_{\infty}=\left[\begin{array}{ll}
M_{11} & M_{12} \\
M_{21} & M_{22}
\end{array}\right]=\left[\begin{array}{c|cc}
\bar{A} & \bar{B}_{1} & \bar{B}_{2} \\
\hline \bar{C}_{1} & \bar{D}_{11} & \bar{D}_{12} \\
\bar{C}_{2} & \bar{D}_{21} & \bar{D}_{22}
\end{array}\right]
$$

で与えると, 中心解コントローラ $K$ は,

$$
K=\mathcal{F}_{l}\left(M_{\infty}, 0\right)=M_{11}
$$

として得られる。この $K$ に対して提案手法を適用するた めには，提案アルゴリズムの Step 1 において, $K$ と $G_{p}$ の既約因子を求める必要がある。 $K$ の既約因子の一組は, $M_{\infty}$ の実現から次のように計算することができる ${ }^{(4)}$ 。

$$
\left[\begin{array}{c}
X_{r} \\
Y_{r}
\end{array}\right]=\left[\begin{array}{c|c}
\bar{A}-\bar{B}_{1} \bar{D}_{21}^{-1} \bar{C}_{2} & \bar{B}_{1} \bar{D}_{21}^{-1} \\
\hline \bar{C}_{1}-\bar{D}_{11} \bar{D}_{21}^{-1} \bar{C}_{2} & \bar{D}_{11} \bar{D}_{21}^{-1} \\
-\bar{D}_{21}^{-1} \bar{C}_{2} & \bar{D}_{21}^{-1}
\end{array}\right] \ldots
$$




$$
\left[\begin{array}{c}
X_{l}^{\mathrm{T}} \\
Y_{l}^{\mathrm{T}}
\end{array}\right]=\left[\begin{array}{c|c}
\left(\bar{A}-\bar{B}_{2} \bar{D}_{12}^{-1} \bar{C}_{1}\right)^{\mathrm{T}} & \left(\bar{D}_{12}^{-1} \bar{C}_{1}\right)^{\mathrm{T}} \\
\hline\left(\bar{B}_{1}-\bar{B}_{2} \bar{D}_{12}^{-1} \bar{D}_{11}\right)^{\mathrm{T}} & \left(\bar{D}_{12}^{-1} \bar{D}_{11}\right)^{\mathrm{T}} \\
\left(-\bar{B}_{2} \bar{D}_{12}^{-1}\right)^{\mathrm{T}} & \left(\bar{D}_{12}^{-1}\right)^{\mathrm{T}}
\end{array}\right]
$$

ここでは，これらを $K$ の既約因子として用いる。 $G_{p}$ に ついては，正規既約分解を利用し，必要ならば，(36) 式の ダブルベズー等式が成立するように $G_{p}$ の既約因子を再選 択する。また，一般化グラミアンは唯一でないので，提案 アルゴリズムの Step 2 に打いて, $K$ の低次元化に利用す るものを定める必要がある。一般化グラミアンの性質 2 で 示したように，制御システム $T_{z w}$ の一般化グラミアン $\mathcal{P}$ $(\mathcal{Q})$ は, $T_{z w}$ のグラミアン $\mathcal{M}(\mathcal{N})$ と $\tilde{T}_{z w}$ のグラミア ン $\tilde{\mathcal{M}}(\tilde{\mathcal{N}})$ の和となる。M $(\mathcal{N})$ は定数であるため, $\tilde{\mathcal{M}}$ $(\tilde{\mathcal{N}})$ の影響を小さくすることで誤差上界の保守性をある 程度小さくすることができる。これは，また，各サブシス テムについてもいえる。さらに，誤差上界はコントローラ の既約因子に対応した部分 $\mathcal{P}_{k}$ 拉よび $\mathcal{Q}_{k}$ で決定されるた め, ここではZhou ら ${ }^{(6)} や \mathrm{Oh}$ ら $^{(9)}$ に準じ, $\operatorname{tr}\left(\mathcal{P}_{k}\right)$ およ び $\operatorname{tr}\left(\mathcal{Q}_{k}\right)$ が最小となるものを低次元化に利用する一般化 グラミアンとして選ぶ。

なお，本例題では，以下の手法を用いて比較を行う。

- 重みなし既約因子平衡打ち切り法 ${ }^{(4)}$ (5) (UWCF: UnWeighted Coprime Factor reduction)

- 性能重みつき既約因子平衡打ち切り法 (4) (5) (PWCF： Performance Weighted Coprime Factor reduction)

- 提案手法

〔例題 1〕（1 自由度振動系） 図 3 に示す一般化プラント $G$ に対して, 制御システム $T_{z w}=\mathcal{F}_{l}(G, K)$ の $\mathcal{H}_{\infty}$ ) ルムが設定值 $\gamma=0.7140$ 未満となる中心解コントロー ラ $K$ を設計する。各パラメータは次のとおりである。

$$
\begin{aligned}
& P=\frac{100}{s^{2}+0.1 s+100} \\
& W_{z 1}=5 \frac{0.1 s+1}{100 s+1}, \quad W_{z 2}=0.3 \frac{10 s+1}{0.01 s+1}
\end{aligned}
$$

設計されたコントローラ $K$ は 4 次元である。また， $\left\|T_{z w}\right\|_{\infty}=0.7073$ となり, 設計仕様 $\left\|T_{z w}\right\|_{\infty}<0.7140$ を満たす。結果を表 1 に示す。

〔例題 2〕（無人高機動航空機 HIMAT ${ }^{(10)}$ ) 図 3 に示 す一般化プラント $G$ に対して, 制御システム $T_{z w}=$ $\mathcal{F}_{l}(G, K)$ の $\mathcal{H}_{\infty}$ ノルムが設定值 $\gamma=2.0000$ 未満とな る中心解コントローラ $K$ を設計する。各パラメータは 次のとおりである。

$$
\begin{aligned}
P & =\left[\begin{array}{l|l}
A_{p} & B_{p} \\
\hline C_{p} & 0
\end{array}\right] \\
A_{p} & =\left[\begin{array}{cccc}
-0.0226 & -36.6 & -18.9 & -32.1 \\
0 & -1.9 & 0.983 & 0 \\
0.0123 & -11.7 & -2.63 & 0 \\
0 & 0 & 1 & 0
\end{array}\right]
\end{aligned}
$$

† PWCF 法では重みつきの低次元化問題を解く必要がある。ここで は，Oh ら (9)の重みつき低次元化法を利用する。

$$
B_{p}=\left[\begin{array}{cc}
0 & 0 \\
-0.414 & 0 \\
-77.8 & 22.4 \\
0 & 0
\end{array}\right], C_{p}=\left[\begin{array}{cccc}
0 & 57.3 & 0 & 0 \\
0 & 0 & 0 & 57.3
\end{array}\right]
$$

$$
W_{z 1}=\left[\begin{array}{cc}
\frac{50(s+100)}{s+10000} & 0 \\
0 & \frac{50(s+100)}{s+10000}
\end{array}\right]
$$$$
W_{z 2}=\left[\begin{array}{cc}
\frac{0.5(s+3)}{s+0.03} & 0 \\
0 & \frac{0.5(s+3)}{s+0.03}
\end{array}\right]
$$

設計されたコントローラ $K$ 礼 8 次元である。また， $\left\|T_{z w}\right\|_{\infty}=1.9455$ となり, 設計仕様 $\left\|T_{z w}\right\|_{\infty}<2.0000$ を満たす。結果を表 2 に示す。

表 1 および 2 から確認できるように，提案手法では，平衡 化する一般化刍ラアンを適切に選ぶことで，すべての次 数において性能劣化を抑えることが可能となっている（例 題 2 の 7 次元目では, 他の手法と同様に, 劣化のない低次 元化コントローラを得ることが可能となっている)。さらに 同表より, 平衡化する一般化グラミアンによって, 性能劣化 の抑制が見られる次数がそれぞれ異なることがわかる。こ れは,「一般化グラミアンを組み合わせて平衡化する」とい う提案手法の特徵が性能劣化の抑制に効果的であるという ことを示している。また，従来手法と異なり，提案手法で は既約分解で表現されたサブシステム $T_{i j}^{f}$ (これは閉ルー プ構造を持つサブシステム $T_{z_{i} w_{j}}$ と等価である) を対象に 低次元化を行うため, 設計時に付加される重み $W_{z 1}$ およ び $W_{z 2}$ の特性を陽に考慮することができる。これにより， 提案手法では制御システムの閉ループ特性（閉ループ安定 性抢よび $\mathcal{H}_{\infty}$ 制御性能) を直接的に考慮することができ ると考えられる。この結果と提案手法の特徵（サブシステ ムの一般化グラミアンを組み合わせて平衡化すること）か ら, 提案手法は, 例題 1 および 2 のように感度関数や相補 感度関数などの複数の伝達関数を同時に考慮した $\mathcal{H}_{\infty}$ 制 御問題（混合感度問題など）に対して有効となると考えら れる。

\section{6. おわりに}

本論文では，一般化グラミアンの組合せによるコントロー ラの低次元化について述べた。今回提案したコントローラ 低次元化法は, 既約分解を用いて記述された各サブシステ ム $T_{i j}^{f}$ においてブロック対角の一般化グラミアン $\mathcal{P}\left\{T_{i j}^{f}\right\}$ および $\mathcal{Q}\left\{T_{i j}^{f}\right\}$ を求め, これらを組み合わせて平衡化する ことで, コントローラの低次元化によって生じる性能 $\left(\mathcal{H}_{\infty}\right.$ 性能）の劣化抑制を目指した手法である。また，提案手法 の有効性を確認するため, 数值例（1 自由度振動系および 無人高機動航空機 $\operatorname{HIMAT}^{(10)}$ の $\mathcal{H}_{\infty}$ 制御問題）を用いて 従来の手法と提案手法の比較を行った。その結果, 提案手 法は性能劣化の抑制に有効であることが確認できた。

(平成 18 年 9 月 25 日受付, 平成 19 年 5 月 15 日再受付) 
表 1 例題 1 における $\hat{T}_{z w}=\mathcal{F}_{l}(G, \hat{K})$ の $\mathcal{H}_{\infty}$ ノルム $\left(\left\|T_{z w}\right\|_{\infty}=0.7073\right)$

Table 1. $\quad \mathcal{H}_{\infty}$ norm of $\hat{T}_{z w}=\mathcal{F}_{l}(G, \hat{K})$ in the example $1\left(\left\|T_{z w}\right\|_{\infty}=0.7073\right)$

\begin{tabular}{c|c|c|c|c|c|c|c|c|c}
\hline \multirow{2}{*}{$\begin{array}{c}\text { Order } \\
\text { of } \hat{K}\end{array}$} & \multicolumn{2}{|c|}{ UWCF } & \multicolumn{2}{|c|}{ PWCF } & \multicolumn{6}{c}{ Proposed method } \\
\cline { 2 - 10 } & Right ${ }^{\sharp 1}$ & Left $\sharp 1$ & Right & Left & $\begin{array}{c}\left(\mathcal{P}\left\{T_{11}^{r}\right\},\right. \\
\left.\mathcal{Q}\left\{T_{11}^{l}\right\}\right)_{b}\end{array}$ & $\begin{array}{c}\left(\mathcal{P}\left\{T_{21}^{r}\right\},\right. \\
\left.\mathcal{Q}\left\{T_{11}^{l}\right\}\right)_{b}\end{array}$ & $\begin{array}{c}\left(\mathcal{P}\left\{T_{12}^{r}\right\},\right. \\
\left.\mathcal{Q}\left\{T_{22}^{l}\right\}\right)_{b}\end{array}$ & $\begin{array}{c}\left(\mathcal{P}\left\{T_{12}^{r}\right\},\right. \\
\left.\mathcal{Q}\left\{T_{12}^{r}\right\}\right)_{b}\end{array}$ & \begin{tabular}{c}
$\left(\mathcal{P}\left\{T_{22}^{l}\right\}\right.$, \\
$\left.\mathcal{Q}\left\{T_{12}^{r}\right\}\right)_{b}$ \\
\hline 1
\end{tabular} \\
\hline 2.0746 & 7.0540 & 7.0746 & $\mathrm{U}$ & 8.4276 & 8.4233 & $\underline{7.0465}$ & $\mathrm{U}$ & 7.0580 \\
3 & 7.0746 & 1.7518 & 7.0746 & 1.7518 & $\underline{1.2711}$ & $\underline{1.2657}$ & 7.0821 & 2.3620 & $\mathrm{U}$ \\
\hline
\end{tabular}

${ }^{\sharp 1}$ Controller reduction with Right or Left coprime factor of $K \quad{ }^{\sharp 2}$ Closed-loop system $\hat{T}_{z w}$ is unstable

表 2 例題 2 における $\hat{T}_{z w}=\mathcal{F}_{l}(G, \hat{K})$ の $\mathcal{H}_{\infty}$ ノルム $\left(\left\|T_{z w}\right\|_{\infty}=1.9455\right)$

Table 2. $\quad \mathcal{H}_{\infty}$ norm of $\hat{T}_{z w}=\mathcal{F}_{l}(G, \hat{K})$ in the example $2\left(\left\|T_{z w}\right\|_{\infty}=1.9455\right)$

\begin{tabular}{c|c|c|c|c|c|c|c|c|c}
\hline \multirow{2}{*}{$\begin{array}{c}\text { Order } \\
\text { of } \hat{K}\end{array}$} & \multicolumn{2}{|c|}{ UWCF } & \multicolumn{2}{c|}{ PWCF } & \multicolumn{6}{c}{ Proposed method } \\
\cline { 2 - 9 } & Right & Left & Right & Left & $\begin{array}{c}\left(\mathcal{P}\left\{T_{11}^{r}\right\},\right. \\
\left.\mathcal{Q}\left\{T_{22}^{r}\right\}\right)_{b}\end{array}$ & $\begin{array}{c}\left(\mathcal{P}\left\{T_{11}^{r}\right\},\right. \\
\left.\mathcal{Q}\left\{T_{11}^{r}\right\}\right)_{b}\end{array}$ & $\begin{array}{c}\left(\mathcal{P}\left\{T_{12}^{r}\right\},\right. \\
\left.\mathcal{Q}\left\{T_{12}^{r}\right\}\right)_{b}\end{array}$ & $\begin{array}{c}\left(\mathcal{P}\left\{T_{22}^{r}\right\},\right. \\
\left.\mathcal{Q}\left\{T_{22}^{l}\right\}\right)_{b}\end{array}$ & $\begin{array}{c}\left(\mathcal{P}\left\{T_{11}^{l}\right\},\right. \\
\left.\mathcal{Q}\left\{T_{11}^{l}\right\}\right)_{b}\end{array}$ \\
\hline 1 & 328.96 & $\mathrm{U}$ & 330.69 & $\mathrm{U}$ & 334.78 & 336.74 & $\underline{325.50}$ & $\mathrm{U}$ & 40521 \\
2 & 163.46 & $\mathrm{U}$ & 182.80 & $\mathrm{U}$ & 178.87 & $\underline{74.922}$ & 362.86 & $\mathrm{U}$ & 1746.3 \\
3 & 122.60 & $\mathrm{U}$ & 186.85 & $\mathrm{U}$ & $\underline{102.25}$ & $\underline{95.911}$ & 174.40 & $\mathrm{U}$ & $\mathrm{U}$ \\
4 & 85.623 & $\mathrm{U}$ & 147.47 & $\mathrm{U}$ & $\underline{19.795}$ & $\underline{77.187}$ & $\underline{78.323}$ & $\mathrm{U}$ & 196.40 \\
5 & 27.552 & $\mathrm{U}$ & 4.7331 & $\mathrm{U}$ & $\underline{3.2632}$ & 114.60 & 80.782 & $\mathrm{U}$ & 149.11 \\
6 & 2.3843 & 11.086 & 2.1915 & 9.3506 & $\underline{1.9806}$ & 93.353 & 95.177 & 3.3958 & 66.770 \\
7 & 1.9455 & 1.9455 & 1.9455 & 1.9455 & 1.9455 & 8.4615 & 2.8085 & 1.9455 & 1.9755 \\
\hline
\end{tabular}

\section{文献}

(1) D. Enns: "Model reduction for control system design", Ph.D Dissertation, Department of Aeronautics and Astronautics, Stanford university, Stanford, CA (1984)

(2) C.A. Lin and T.Y. Chiu: "Model reduction via frequency weighted balanced realization", control theory and advanced technology, Vol.8, No.2, pp.341-351 (1992)

(3) G. Wang, V. Sreeram, and W. Q. Liu: "A New FrequencyWeighted Balanced Truncation Method and an Error Bound", IEEE Trans. Automat. Contr., Vol.44, No.9, pp.1734-1737 (1999)

(4) K. Zhou, J.C. Doyle, and K. Glover: Robust and optimal control, Prentice-Hall (1996) (in Japanese) 劉 康志・羅 正華：「ロバスト最適制御」，昭晃堂 (1997)

(5) G. Obinata, B.D.O. Anderson: Model reduction for Control System Design, Springer (2001) (in Japanese) 大日方五郎・B.アアンダーソン:「制御システム設計」, 朝倉書店 (1999)

(6) K. Zhou, C. D'Souza, and J.R. Cloutier: "Structurally balanced controller order reduction with guaranteed closed loop performance", Systems \& Control Letters, 24, pp. 235-242 (1995)

( 7 ) P.M.R. Wortelbore: "Frequency-weighted balanced reduction of closed-loop mechanical servo-systems", Ph.D. Thesis, Delft University of Technology (1994)

(8) B.C. Moore: "Principal component analysis in linear systems", IEEE Trans. Automat. contr., 26, pp.17-32 (1981)

(9) D.C. Oh, and J.H. Kim: "A simple frequency weighted model reduction using structurally balanced truncation: existence of solutions", INT. J. CONTROL, Vol.75, No.15, pp. 1190-1195 (2002)

(10) The Math Works Inc.: $\mu$ Analysis and Synthesis Toolbox User's Guide for Use with MATLAB (version 3), The Math Works Inc. (1998)

（11） 藤森 篤：「ロバスト制御」,コロナ社 (2001)
安 里 健太郎

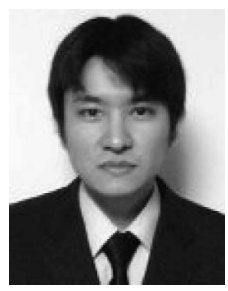

(学生員) 1980 年 6 月 28 日生。 2005 年 3 月琉 球大学大学院理工学研究科電気電子工学専攻修士 課程修了。同年 4 月同大学院理工学研究科総合知 能工学専攻博士課程に進学, 現在に至る。システ ムの低次元化に関する研究に従事。

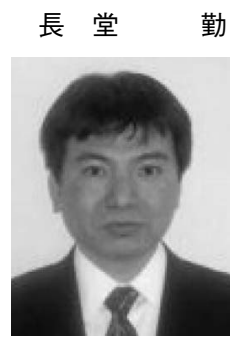

勤 （正員） 1963 年 9 月 17 日生。1988 年 3 月琉球 大学大学院修士課程修了。1991 年 3 月早稲田大 学大学院博士課程後期中退。同年 4 月琉球大学工 学部助手。1997 年同助教授。主として制御器の 低次元化，ロバスト制御に関する研究に従事。博 士 (工学)。

玉 城 史 朗 （正員） 1955 年 11 月 29 日生。1981 年 3 月徳島

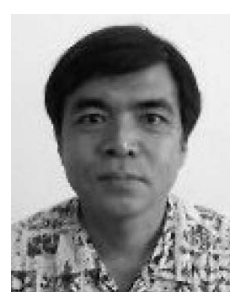
大学大学院修士課程修了。1983 年 7 月大阪大学大 学院博士課程退学。大阪大学助手, 岡山理科大学 講師を経て 1988 年琉球大学工学部助教授。1996 年同大学教授。主としてセンサネットワーク, 自 然エネルギーに関する研究に従事 (工学博士)。 